$44 \mid$ InterAção

\title{
QUARENTA ANOS DE INTEGRAÇÃO DA AMÉRICA DO SUL: A POLÍTICA EXTERNA PARA A REGIÃO DE GEISEL A DILMA I (1974-2014)
}

Diogo Ives ${ }^{1}$

\section{Resumo}

O artigo analisa a política externa que o Brasil implementou em relação aos países sulamericanos no período compreendido entre as presidências de Ernesto Geisel (1974-79) e Dilma Rousseff I (2011-14). Ao longo dos quarenta anos, observou-se um movimento de aproximação constante em direção à vizinhança, porém o objetivo dessa ação sofreu uma breve reinterpretação durante os governos de Fernando Collor (1990-92) e Fernando Henrique Cardoso I (1995-98). Nestes dois momentos, o projeto de autonomia regional em relação aos Estados Unidos, que predominou no período, foi substituído por um projeto de interdependência assimétrica com a grande potência.

Palavras-chave: Política Externa Brasileira; América do Sul; Integração Regional.

\begin{abstract}
The article analyzes the Brazilian foreign policy to the South-American countries in the period between the presidencies of Ernesto Geisel (1974-79) and Dilma Rousseff I (2011-14 ). Over the forty years, there was a steady movement of approach toward the neighborhood, but the goal of this action suffered a brief reinterpretation during the governments of Fernando Collor (1990-92 ) and Fernando Henrique Cardoso I (1995-98 ). In those two moments, the project of regional autonomy against the United States, which was predominant in the period, was replaced by an interdependence project with the great power.
\end{abstract}

Key words: Brazilian Foreign Policy; South America; Regional Integration.

\section{INTRODUÇÃO}

Segundo Ricardo Sennes (2003), o governo Geisel inaugurou uma nova matriz na política externa brasileira, baseada em um conjunto diferente de

${ }^{1}$ Mestrando em Ciência Política da Universidade Federal do Rio Grande do Sul. 
45 | InterAção

percepções, estratégias e valores em relação ao que estava vigente anteriormente. Uma das características dessa nova postura foi um movimento de aproximação em direção a países da América do Sul. O objetivo deste artigo foi investigar em que medida essa linha de ação inaugurada por Geisel influenciou a política regional do Brasil nas décadas seguintes e por quais processos de continuidade ou mudança ela passou até se chegar ao final do primeiro mandato de Dilma Rousseff, em 2014.

O conceito teórico de "matriz de política externa" de Sennes é útil para a comparação de períodos históricos curtos, na medida em que entende que um modelo de inserção internacional pode perpassar diferentes governos para além de um mandato presidencial sem, contudo, combiná-los sob um mesmo paradigma de desenvolvimento econômico que não permite ver nuances entre eles. Esse instrumento analítico também permite distinguir, nos termos de Hermann (1990), entre meras mudanças de ajuste na condução da política externa e alterações mais profundas em relação ao programa, aos objetivos e à orientação internacional de um país.

\section{AS BASES DA INTEGRAÇÃO SUL-AMERICANA}

O governo Geisel (1974-79) implementou uma política externa pragmática e autonomista que levou o Brasil para mais perto da América do Sul. O governo buscou aumentar sua presença na região com o objetivo de se tornar a potência preponderante e reduzir a influência dos Estados Unidos. A superpotência passou a ser vista como decadente após o choque de petróleo de 1973 ser imposto pelos países árabes e a sua derrota no Vietnã ser selada pelos Acordos de Paris no mesmo ano. Em contraste, o Terceiro Mundo era visto 
46 | InterAção

como um novo polo de poder internacional, do qual o Brasil deveria se aproximar para não ficar isolado (GONÇALVES E MIYAMOTO, 1993).

A relação com os Estados Unidos, central desde o início da Guerra Fria, havia se tensionado. Washington, antes apoiador do regime anticomunista, passou a se incomodar com os seus projetos de autonomia, especialmente no campo nuclear. Jimmy Carter passou a deslegitimá-lo por meio de críticas em relação ao descumprimento de direitos humanos. Geisel revidou denunciando, em 1977, os acordos militares assinados com a superpotência. Economicamente, avaliava-se que as trocas comerciais com os Estados Unidos tampouco indicavam um bom futuro, dada uma crescente perda de complementaridade com o avanço da industrialização brasileira e a adoção de medidas protecionistas por Washington no início dos anos 1970 (SILVA, 2005). A diversificação de parceiros comerciais passou a ser perseguida pelo Brasil nos demais continentes.

Com relação à vizinhança, o governo Geisel buscou implementar um projeto de unidade continental desvinculada dos Estados Unidos (SOUTO MAIOR, 1996). Embora ainda guiado pelo conceito de América Latina, as ações de aproximação se deram sobretudo com países da América do Sul. Uma atenção prioritária foi dada à distensão da relação com a Argentina, que estava desconfiada com o aumento de poder que o Brasil teria na bacia do Prata após assinar o Tratado de Itaipu com o Paraguai, em 1973. O governo argentino reagiu anunciando a construção da usina de Corpus, também com o Paraguai, e assinando acordos de cooperação econômica com o Uruguai. O Itamaraty procurou aumentar o diálogo bilateral e coordenar os projetos de Itaipu e Corpus.

Outra ação regional de destaque foi a assinatura do Tratado de Cooperação Multilateral da Amazônia, em 1978, com Peru, Equador, Colômbia, 
47 InterAção

Venezuela, Bolívia, Suriname e Guiana. As metas principais eram incentivar a pesquisa científica e integrar a região amazônica por obras de navegação, rodovias, ferrovias, aeroportos, telecomunicações e redes elétricas. Além de uma aproximação em direção aos vizinhos, tratava-se de uma resposta a iniciativas estrangeiras que queriam internacionalizar a floresta para preservar seus recursos, o que criaria uma espécie de reserva de materiais estratégicos que não poderia ser utilizada por aqueles países em seu desenvolvimento (ELIBIO JR., 2012).

Com o Pacto Amazônico, o Brasil também esperava balancear o Pacto Andino, do qual não fazia parte (GONÇALVES E MIYAMOTO, 1993). O bloco havia sido criado em 1969 entre Colômbia, Peru, Equador, Bolívia e Chile, recebendo a adesão da Venezuela em 1973. Seus objetivos incluíam estimular o comércio, a industrialização a partir da formação de economias de escala, a integração física entre os países e a regulamentação das atividades de empresas multinacionais. O Chile deixou o grupo em 1976 após a chegada ao poder de Augusto Pinochet, que iniciou um programa econômico neoliberal incompatível com os propósitos do bloco.

O governo Figueiredo (1979-85) deu continuidade à política externa de Geisel, porém sob uma conjuntura internacional diferente. Houve uma intensificação da Guerra Fria após Ronald Reagan assumir a presidência dos Estados Unidos, em 1981, o que significou uma maior cobrança de Washington sobre o alinhamento dos países do Terceiro Mundo. Em busca de uma melhora das relações bilaterais, Reagan chegou a visitar o Brasil, mas não conseguiu o apoio de Figueiredo à sua proposta de criar um acordo de defesa do Atlântico Sul (SENNES, 2003). O governo brasileiro manteve a postura de afastar a superpotência da sua vizinhança. 
48 | InterAção

O esforço de aproximação regional também foi continuado e intensificado. Figueiredo visitou e fez acordos de cooperação com quase todos os países da América do Sul. A relação com a Argentina atingiu um elevado nível de cordialidade por meio do Acordo Multilateral de Corpus-Itaipu de 1979 (assinado ao lado do Paraguai) e de entendimentos na área nuclear para reduzir desconfianças (BARRETO, 2001). Também lhe foi dado apoio contra as potências ocidentais durante a Guerra das Malvinas de 1982, inclusive por meio da venda secretas de aviões de combate (VIZENTINI, 2008).

Com relação ao norte da região, o governo brasileiro deu andamento ao Tratado de Cooperação Amazônica, que foi ratificado internamente em 1980, mesmo ano em que começou a ser operacionalizado na primeira reunião entre os chanceleres do acordo (PEREIRA, 2010). Um memorando de entendimento foi ainda assinado entre o Brasil e o Pacto Andino, em 1979, para troca de informações, consulta e coordenação a nível ministerial (BARRETO, 2001). O Brasil também atuou como mediador entre Equador e Peru após conflitos fronteiriços eclodirem entre os dois países (VIZENTINI, 1998).

Paulatinamente, o governo Figueiredo foi sendo paralisado diante da crise da dívida externa. O pagamento do financiamento contraído para o Brasil se industrializar e importar combustível nos anos anteriores ficou comprometido com os choques do petróleo e com um aumento internacional das taxas de juros iniciado pelos Estados Unidos em 1979. A entrada de novos capitais no Brasil logo caiu. Diante da necessidade de adquirir divisas, Figueiredo passou a buscar superávits comerciais. Tendo em vista que o Terceiro Mundo e a Europa retraíam as importações em face de crises econômicas, os fluxos comerciais acabaram se reconcentrando nos Estados Unidos (SENNES, 2003). 
49 | InterAção

Ao mesmo tempo, surgiram fortes pressões estadunidenses para que o Brasil mudasse seu modelo desenvolvimentista então em vigor na direção de uma maior liberalização econômica. A criação do Programa de Promoção Comercial no Exterior, em 1979, e a oferta de incentivos fiscais para as exportações de manufaturados, a partir de 1981, foram criticadas como concorrência desleal e revidadas com impostos sobre as vendas brasileiras (SILVA, 2005). Outros conflitos comerciais, inclusive dentro do GATT, seriam incitados pelos Estados Unidos ao longo da década de 1980 para o Brasil abandonar seu protecionismo.

A política externa de Reagan e os problemas com dívida externa que logo se alastraram regionalmente contribuíram para a estagnação da Associação Latino-Americana de Integração (ALADI), criada em 1980 para substituir a Associação Latino-Americana de Livre Comércio (ALALC), de 1960. Segundo Pereira (2010):

as metas do novo tratado, menos pretensiosas e mais flexíveis, conservaram o princípio multilateralista de criação de um mercado comum [...], [mas] a recessão generalizada e a consequente carência de capitais representaram entraves para os investimentos intrarregionais, condenando esta iniciativa a não obter êxito" (PEREIRA, 2010, p. 123).

O governo Sarney (1985-1990) foi dominado pelos temas da transição democrática e da crise econômica interna. A conjuntura internacional foi marcada por uma perda cada vez maior de poder e articulação dos países subdesenvolvidos. Os Estados Unidos, incomodados com a maioria terceiromundista nos fóruns multilaterais, trabalharam para enfraquecê-los. Discussões sobre uma nova ordem econômica internacional deram lugar a pautas que inverteram o ônus dos problemas contra o Sul, como violações de direitos humanos, déficits de democracia liberal, problemas ambientais, narcotráfico e migrações (CORREA, 1996). 
50 | InterAção

Apesar desse cenário desfavorável, o governo brasileiro manteve a mesma matriz de política externa inaugurada por Geisel, assim como resistiu ao abandono do modelo econômico desenvolvimentista. $\mathrm{O}$ fechamento do espaço terceiro-mundista no sistema internacional fazia a América do Sul ser valorizada ainda mais como alternativa estratégica, sobretudo em um momento no qual Washington aumentava as pressões para o Brasil abandonar a autonomia em questões como patentes, informática e energia nuclear (VIZENTINI, 2008).

Embora nem sempre possível, houve resistência às vontades da superpotência, como a aprovação na ONU de um projeto brasileiro que declarava o Atlântico Sul como uma zona de paz e cooperação (ZOPACAS, que passaria a contar com reuniões ministeriais periódicas entre os países da área), a suspensão do pagamento de juros da dívida em 1987 e a recusa contínua de assinar o Tratado de Não-Proliferação Nuclear (PEREIRA, 2010). A integração dos povos latino-americanos em direção a uma comunidade de nações foi cristalizada na Constituição de 1988 como um objetivo brasileiro.

Sarney visitou todos os países sul-americanos e recebeu praticamente todos os presidentes da região, assim como compareceu às posses de vários deles, algo pouco usual até então. Essa diplomacia presidencial foi útil para construir um respaldo por parte dos países amazônicos em torno do Brasil no debate internacional sobre meio-ambiente, no qual vinha sendo transformado em uma espécie de vilão por causa das queimadas na Amazônia (CORREA, 1996). A articulação construída pelo Pacto Amazônico nos anos anteriores teve um papel importante nesse resultado.

No período, o Brasil formou ainda o Grupo de Apoio a Contadora com Argentina, Peru e Uruguai para secundar os esforços do Grupo de Contadora (México, Colômbia, Venezuela e Panamá), o qual trabalhava para resolver 
51 InterAção

conflitos bélicos centro-americanos opondo-se à política militarista dos Estados Unidos. Os dois grupos se uniram e formaram o Grupo do Rio, em 1986, originando pela primeira vez um canal latino-americano autônomo de ação diplomática (CORREA, 1996).

O principal parceiro brasileiro continuou sendo a Argentina, com quem o bom relacionamento construído anteriormente se consolidou. Em 1986, os dois países criaram o Programa de Integração e Cooperação Econômica (PICE) para intensificar trocas em diversas áreas, assim como abriram seus programas nucleares para conhecimento mútuo. Em 1988, firmaram o Tratado de Integração, Cooperação e Desenvolvimento e, com o Uruguai, a Decisão Tripartite. Os entendimentos objetivavam a criação de um mercado comum entre as partes, colocando o projeto multilateral da ALADI em bases mais realistas (PEREIRA, 2010).

De Geisel a Sarney, o Brasil não atingiu a condição de potência hegemônica regional, apesar de conquistar uma influência maior, já que suas ações eram mais discretas do que intervencionistas, enquanto a projeção dos Estados Unidos se manteve elevada (SENNES, 2003). Ao final da década de 1980, a superpotência havia se consolidado como o principal parceiro comercial brasileiro. Foi apenas com o fim da ordem bipolar que a América do Sul foi eliminada como área de interesse prioritária para Washington. No entanto, demorariam alguns anos até o Brasil aproveitar esse vácuo político.

\section{NEOLIBERALISMO E INTERDEPEDÊNCIA ASSIMÉTRICA}

Nos anos 1990, a política externa brasileira passou por uma nova mudança estrutural em relação ao que vinha sendo implantado desde Geisel 
52 | InterAção

(SENNES, 2003). A matriz inaugurada pelo governo Collor (1990-1992) assumiu a adoção de medidas neoliberais como paradigma de desenvolvimento e a inserção na globalização como o objetivo externo principal. Apostava-se que o receituário do Consenso de Washington seria capaz de tirar o Brasil da crise econômica que persistia e que um vínculo maior com a potência vencedora da Guerra Fria traria benefícios políticos ao Brasil. Diminuir os atritos com os Estados Unidos aparecia agora como uma postura mais atraente.

Governados por George Bush, os Estados Unidos mantiveram pressões sobre a América Latina para a liberalização dos seus mercados internos. Embora consolidado como a maior potência militar no pós-Guerra Fria, o país enfrentava uma concorrência econômica maior por parte de europeus e japoneses. Recuperar e abrir as economias latino-americanas às suas empresas foi identificado como um caminho para se ganhar vantagem nesse contexto. $\mathrm{O}$ Plano Brady, a Iniciativa para as Américas e o NAFTA foram ações políticas propostas por Bush nesse sentido.

Essa pressão alterou a forma como o Brasil encarava a aproximação com a sua vizinhança. O eixo regional continuou tendo uma grande importância, porém não mais com vistas à formação de um espaço autônomo. A integração era agora tratada como um meio para o Brasil colocar-se como um entusiasta da globalização. Partindo do núcleo-duro formado com a Argentina, foi estabelecido o Mercosul, ao lado de Uruguai e Paraguai, em 1991. Procurava-se mostrar aos Estados Unidos uma boa vontade em relação à abertura externa para posteriormente se poder negociar um tratado de comércio bilateral (SILVA, 2009).

A diplomacia de Collor também deu mais atenção aos novos temas propostos pelos países desenvolvidos na agenda internacional, em uma tentativa de influir sobre eles nas discussões multilaterais. O caso mais 
53 | InterAção

emblemático foi a realização, em 1992, da Rio+20, conferência da ONU para discutir problemas ambientais. $\mathrm{O}$ evento foi importante para agregar demandas de desenvolvimento socioeconômico ao tema - consagrando a expressão "desenvolvimento sustentável" -, assim como reduzir as ameaças internacionais que ainda pairavam sobre o controle da Amazônia (CERVO \& BUENO, 2011).

O projeto neoliberal teve sua velocidade reduzida com o impeachment de Collor em 1992. Embora convivendo com liberais no ministério da Fazenda, o governo Itamar (1992-94) retomou alguns princípios desenvolvimentistas, o que, para a política externa, significou um retorno à estratégia de conformação de um entorno mais autônomo em relação aos Estados Unidos. Enquanto Washington prometia o ingresso no NAFTA aos países que implantassem reformas neoliberais, o Brasil tentou atrair seus vizinhos por meio do projeto da Aliança de Livre Comércio Sul-Americana (ALCSA). Ideias de uma integração maior foram enterradas após o México se associar aos Estados Unidos e ao Canadá.

Por meio da ALCSA, o governo esperava garantir um espaço para a venda dos produtos brasileiros industrializados, que tinham dificuldade de competir em outras partes do mundo. Segundo Vizentini (2008), o custo para o Brasil de oferecer fatias do seu mercado interno aos vizinhos era relativamente baixo - dadas as suas economias pequenas - e compensável com os ganhos de longo prazo. Ao mesmo tempo, o Brasil iniciou negociações para a adesão da Bolívia e do Chile ao Mercosul na posição de países associados, o que se efetivaria no governo seguinte.

A preocupação com a soberania e o desenvolvimento da Amazônia ganhou novo ímpeto no projeto regional. O Brasil criou os sistemas de vigilância e de proteção do espaço aéreo (SIVAM e SIPAM) e lançou a Iniciativa 
54 InterAção

Amazônica com Venezuela, Bolívia e Peru para estimular a cooperação econômica. Outra meta brasileira que começava a ganhar importância era a conquista de uma saída para o Pacífico por meio da construção de infraestrutura transfronteiriça. Uma comissão chegou a ser montada com o Chile para estudar uma conexão biocêanica (VIZENTINI, 2008).

O novo objetivo era explicado pelo crescimento econômico sem paralelo que o leste asiático registrava. Além de ganhos comerciais, calculava-se que um maior contato do Brasil com aquela região poderia abrir possibilidades de concertação política com as várias potências locais (CANANI, 2004). Além disso, a APEC, bloco econômico criado em 1989 pelos Estados Unidos para aumentar as trocas com os países daquela região, estava ganhando a adesão de países latino-americanos - México em 1993 e Chile em 1994.

Apesar do breve hiato, o governo Cardoso I (1995-1998) reativou a implantação da matriz neoliberal no Brasil iniciada por Collor. A consolidação do Plano Real, lançado em 1994, era dependente de uma maior abertura econômica. A fim de manter uma inflação baixa, o programa estipulava um câmbio valorizado para estimular importações e uma taxa de juros alta para incentivar a captação de recursos que cobrissem os esperados déficits comerciais. No discurso internacional, o país voltou a se mostrar um entusiasta da globalização.

A maior interdependência que se buscava com o mercado internacional implicava a adoção de uma política externa mais cooperativa com os grandes centros econômicos, especialmente os Estados Unidos. Contenciosos com esse país foram resolvidos, como a decisão de se assinar o TNP, bem como se aceitou negociar a formação de uma grande área de livre-comércio no continente americano, reformulada agora no projeto da Área de Livre Comércio das Américas (ALCA) de Bill Clinton. 
55 | InterAção

Contudo, déficits comerciais começaram a se firmar na relação com os Estados Unidos desde que a abertura comercial havia sido promovida no início dos anos 1990, o que fez o governo brasileiro não descuidar da importância de se aproximar das outras áreas do mundo. $\mathrm{O}$ atrelamento que o México havia decidido implementar com seu vizinho através do NAFTA havia provocado uma crise econômica naquele país em dezembro de 1994, o que também contribuiu para a postura brasileira.

No plano regional, essa linha de ação significou investimentos contínuos no Mercosul, interpretado agora como uma espécie de estágio que prepararia as economias locais para maiores aberturas comerciais posteriormente, evitando choques de liberalização (SILVA, 2005). O bloco assinou um acordo com a União Europeia com vistas à facilitação do comércio. O mesmo foi feito com a Comunidade Andina - reformulação liberal do Pacto Andino lançada em 1996 , com a qual também foram acordados projetos de infraestrutura para a criação de corredores de exportação.

No contexto amazônico, foi criada a Organização do Tratado de Cooperação Amazônica para institucionalizar os entendimentos sobre a soberania da região. O Brasil também serviu novamente de mediador entre Peru e Equador para resolver um novo conflito fronteiriço que eclodiu em 1995. Um interesse particular em se aproximar do Peru se devia ao interesse manifesto por FHC em ganhar acesso aos seus portos do Pacífico, o que implicou apoiar o governo de Alberto Fujimori (SILVA, 2005).

O governo Cardoso II (1999-2002) intensificou ainda mais as relações com a América do Sul. Uma crise econômica abateu o país, em 1999, em decorrência de uma maior vulnerabilidade externa criada pela abertura financeira e esfriou o otimismo em relação à globalização e ao neoliberalismo (SILVA, 2005). A relação com os Estados Unidos ficou mais difícil, seja pela 
56 | InterAção

maior resistência brasileira ante a ALCA, seja porque, após o 11 de Setembro, George W. Bush passou a aumentar ações unilaterais no sistema internacional e a pressionar por iniciativas securitárias na América Latina (VIGEVANI \& CEPALUNI, 2007).

Em 2000, o governo brasileiro organizou a I Cúpula da América do Sul, em Brasília, com a presença de todos os presidentes da região. As principais medidas acordadas no evento foram a conformação de uma área de livrecomércio regional - relembrando os propósitos da ALCSA - e o lançamento da IIRSA para desenvolver conexões de infraestrutura entre os países. Tratava-se em parte de uma tentativa de superar a paralisia que havia se abatido sobre o Mercosul devido à crise brasileira, que fez diminuir as importações provenientes da Argentina, a qual, por sua vez, também passou a comprar menos.

A cúpula demarcava ainda uma lógica diferente em relação à proposta militarista que Washington passou a adotar para controlar os problemas socioeconômicos da região. Foi realizada simbolicamente dois dias depois de ser anunciada uma parceria entre Estados Unidos e Colômbia para o combate ao narcotráfico, a qual incluiria a presença de militares estadunidenses no vizinho brasileiro. A partir do Plano Colômbia, Bush lançou a Iniciativa Regional Andina, em 2001, estendendo recursos também para o Peru e o Equador lutarem contra o que passou a chamar de "narcoterrorismo".

\section{A NOVA AUTONOMIA REGIONAL}

Os governos Lula (2003-2010) sepultaram a matriz neoliberal em crise. Retomou-se a tendência desenvolvimentista de manter um Estado ativo, 
57 | InterAção

atualizado agora para um regime democrático, preocupado em reduzir carências sociais e mais inclinado a articulações com o setor privado. A política externa manteve a postura iniciada do governo anterior de diversificação das relações políticas e econômicas, intensificando parcerias com países em desenvolvimento sem descuidar de negociações com os Estados Unidos.

A integração sul-americana continuou recebendo a principal atenção dentro da política externa. Em 2004, na III Cúpula da América do Sul, foi criada a Comunidade Sul-Americana de Nações (CASA), rebatizada como União de Nações Sul-Americanas (UNASUL) em 2007. O organismo passou por um processo gradual de institucionalização, passando a incluir espaços temáticos de discussão. Sua sede foi construída no meio dos Andes, na cidade equatoriana de Guayaquil, próxima à linha do Equador que divide o Norte e o Sul.

Agrupados no Conselho Sul-Americano de Infraestrutura e Planejamento (COSIPLAN), os projetos de conexão física planejados anteriormente começaram a sair do papel, mas foram redesenhados. A IIRSA, antes muito voltada para o setor privado e planejada para privilegiar o acesso ao mercado internacional, passou a ganhar um financiamento maior do BNDES e a incluir projetos para desenvolver o interior da região e aumentar o comércio entre os países.

Outro espaço de destaque criado na UNASUL foi o Conselho de Defesa Sul-Americano (CDS), estabelecido em 2008, mesmo ano em que os Estados Unidos reativaram uma divisão da sua Marinha que cuida especialmente do Atlântico Sul. O oceano ganhou nova dimensão estratégica com a descoberta do petróleo na camada pré-sal brasileira em 2007. O CDS se somou à vontade do governo brasileiro de reduzir desconfianças militares dos vizinhos. $\mathrm{O}$ esforço 
58 | InterAção

contou ainda com a publicação do Livro Branco de Defesa Nacional e da Política Nacional de Defesa por parte do Brasil.

O governo também articulou a criação de encontros de alto nível entre a América do Sul e os países árabes e africanos (Cúpulas ASA e ASPA). A promoção sul-americana pôde prosperar em grande parte devido a um novo esforço de cooperação com a Argentina. Após passar por uma grave crise econômica em 2001, a vizinha também havia abandonado o neoliberalismo e estava interessada em fortalecer a integração. A coincidência de visões reativou o Mercosul e contribuiu para o fracasso da ALCA. O Mercosul ganhou ainda a adesão de Peru, Equador e Colômbia como membros associados.

Outra parceria estratégica que se firmou no período se deu com a Venezuela. Lula atuou como um aliado do governo de Hugo Chávez, marcado por uma aberta oposição aos Estados Unidos e à sua política militarista no seu entorno. Segundo Bandeira (2006), a Venezuela servia como um contrapeso a Argentina e, ao mesmo tempo, somava com esta para a formação de um triângulo de unidade política e econômica, muito útil para o processo de integração entre o norte e o sul da América do Sul.

Ao final do período, o comércio com o mercado sul-americano registrava importantes resultados. Em 2010, a região recebeu 18,4\% do total das exportações brasileiras, sendo $84 \%$ correspondente a manufaturados - a maior receptora desse tipo de produto brasileiro. Entre 2000 e 2010, a exportação total para a área se ampliou em $245 \%$, enquanto a importação cresceu em $135 \%$. O Brasil registrou superávit com quase todos os países, exceto a Bolívia (COUTO, 2013).

O governo Dilma I (2011-2014) manteve as mesmas estratégias do antecessor em termos de projeto de desenvolvimento e de política externa. Contudo, mostrou-se mais reticente em arcar com os custos da cooperação em 
59 | InterAção

meio à conjuntura de crise econômica internacional, iniciada nos Estados Unidos, em 2008, em decorrência de instabilidades no seu sistema financeiro. Cervo e Lessa (2014) apontam ainda uma menor pró-atividade do governo em relação a assuntos internacionais.

Os Estados Unidos inicialmente tentaram estreitar os laços binacionais a partir da visita de Barack Obama ao Brasil, em 2011, porém a relação esfriou com a divulgação de que Washington espionava instituições do país, o que levou o governo brasileiro a perseguir uma maior autonomia nacional na esfera virtual. A grande potência sofreu ainda um revés com a criação da Comunidade de Estados Latino-Americanos e Caribenhos (CELAC) - uma evolução do Grupo do Rio -, em 2010, que a exclui de articulações regionais e rivaliza com a Organização dos Estados Americanos (OEA), sob seu domínio.

Apesar de oficialmente apoiar o CELAC, a diplomacia brasileira preferiu negociar situações de crise em países da América do Sul no âmbito da UNASUL (SARAIVA 2014). Dentro da região, houve ainda um fortalecimento da visão de mundo liberal. Chile, Peru e Colômbia se aliaram ao México para lançar a Aliança do Pacífico, em 2012, com o objetivo de promover a liberalização econômica e uma maior inserção no leste asiático. Os quatro países aderiram tambmé ao Tratado Trans-Pacífico, projeto liberal de cooperação com países asiáticos liderado pelos Estados Unidos.

Em relação ao Mercosul, houve menos disposição do governo brasileiro para fazer concessões à Argentina, que acabou impondo obstáculos esporádicos às exportações brasileiras e se aproximando mais da China (SARAIVA, 2014). Ainda assim, o bloco se fortaleceu com a entrada da Venezuela como membro pleno, em 2012, e da Guiana e do Suriname como associados, em 2013. A Bolívia iniciou um processo de adesão como membro pleno. A consolidação institucional e política do bloco se fez sentir com a suspensão do Paraguai por 
60 InterAção

um ano após o presidente Fernando Lugo ser deposto em um movimento interno considerado anti-democrático pelos demais governos.

\section{CONSIDERAÇÕES FINAIS}

O movimento de aproximação entre o Brasil e a sua vizinhança lançado no governo Geisel foi mantido ao longo dos quarenta anos seguintes, porém a motivação para a integração passou por uma breve reinterpretação durante os governos Collor e FHC I. Nestes dois momentos, um entusiasmo em relação ao modelo liberal de desenvolvimento e ao protagonismo dos Estados Unidos no sistema internacional geraram uma visão de integração regional mais alinhada às preferências da grande potência. Tal postura não se sustentou quando se verificou que aumentava as vulnerabilidades brasileiras. Nos demais governos, prevaleceu o projeto de Geisel com vistas à formação de uma região mais autônoma em relação a potências extrarregionais.

Em linhas gerais, a política externa regional implementada entre 19742014 se baseou nas seguintes ações: abandono gradual do conceito de "América Latina" para dar lugar à noção de "América do Sul"; posicionamento do Brasil como um elo entre os contextos platino, amazônico e andino; identificação da Argentina como principal parceiro político, seguida por Venezuela e por um país ainda a definir que dê acesso ao Oceano Pacífico; articulação com os países do norte regional para defender a soberania da Amazônia; oposição a políticas militares intervencionistas no continente e no Atlântico Sul; criação de espaços multilaterais de diálogo com os vizinhos, demonstrando uma postura mais cooperativa do que imperialista; e desenvolvimento de infraestrutura intrarregional para dinamizar o comércio e preservar a produção industrial. 
61 InterAção

Vários ainda são os desafios que o Brasil tem para consolidar esse projeto de integração. Vizentini (2008) aponta a persistência de visões liberais que bloqueiam o desenvolvimentismo e a falta de uma correlação de forças no plano doméstico para alterar essa situação. Couto (2013) afirma que a continuidade de déficits comerciais com os vizinhos pode despertar um mal-estar e que os projetos de integração física precisam depender menos das vontades do mercado para serem concretizados. Silva (2014) salienta que ainda falta ao Brasil incorporar melhor a região ao seu projeto de inserção global.

A crescente inserção da China na América do Sul oferece um desafio particular. O gigante asiático se firmou como um importante parceiro comercial de todos os países da área nos últimos anos, o que o posiciona como uma nova potência extrarregional, capaz de influenciar os processos políticos locais. Um sintoma dessa situação já é evidente a partir da reemergência de projetos liberais de concertação que têm o objetivo de facilitar as trocas com a Ásia. Essa postura compromete a ideia brasileira de reservar o mercado sul-americano aos seus produtos industrializados, que têm dificuldade de competir com o baixo custo das mercadorias chinesas.

\section{REFERÊNCIAS}

BANDEIRA, Luiz Alberto Moniz. O Brasil e a América do Sul. In: OLIVEIRA, Henrique Altamani \& LESSA, Antônio Carlos. Relações Internacionais do Brasil: temas e agenda. Volume 1. Editora Saraiva, 2006.

BARRETO, Fernando. Os sucessores do Barão: relações exteriores do Brasil. Paz e Terra, 2001.

CANANI, Ney. Política externa no governo Itamar Franco (1992-1994): continuidade e renovação de paradigma nos anos 90. Porto Alegre: Editora da UFRGS, 2004. 
62 InterAção

CERVO, Amado \& BUENO, Clodoaldo. História da política exterior do Brasil. Brasília: UnB, 2011.

CERVO, Amado \& LESSA, Carlos. O declínio: inserção internacional do Brasil (2011-2014). Rev. Bras. Polít. Int. 57 (2): pp. 133-151, 2014.

CORREA, Luis Felipe Seixas. A política externa de José Sarney. In:

ALBUQUERQUE, José Augusto Guilhon (org.). Sessenta Anos de Política Externa Brasileira (1930-1990). 1996.

COUTO, Leandro. Relações Brasil-América do Sul: a construção inacabada de parceria com o entorno estratégico. In: LESSA, Antônio Carlos \& OLIVEIRA, Henrique Altamani. Parcerias estratégicas do Brasil. Belo Horizonte: Fino Traço, 2013.

ELIBIO JR., Antônio Manoel. De Vargas e Geisel: as estratégias da política externa brasileira para a criação do Tratado de Cooperação Amazônica - TCA (1940-1978). Cadernos do Tempo Presente, edição n. 10, dezembro de 2012.

GONÇALVES, Williams; MIYAMOTO, Shiguenoli. Os militares na política externa brasileira. Estudos Históricos, Rio de Janeiro, vol. 6, n. 12, 1993.

HERMAN, Charles. Changing course: when governments choose to redirect foreign policy. International Studies Quarterly, vol. 34, n. 1, 1990.

PEREIRA, Analúcia Danilevicz. Relações exteriores do Brasil III (1964-1990): do regime militar à nova república. Petrópolis: Vozes, 2010.

SARAIVA, Miriam Gomes. Balanço da política externa de Dilma Rousseff: perspectivas futuras? Lisboa: Relações Internacionais, n. 44, 2014.

SENNES, Ricardo. As mudanças da política externa brasileira nos anos 80: uma potência média recém industrializada. Porto Alegre: Ed. da UFRGS, 2003

SILVA, André Luiz Reis da. As relações entre o Brasil e os Estados Unidos durante o regime militar (1964-1985). Porto Alegre: Ciências e Letras, n.37, 2005.

Do otimismo liberal à globalização assimétrica: a política externa do governo Fernando Henrique Cardoso (1995-2002). Curitiba: Juruá, 2009.

Geometria variável e parcerias estratégicas: a diplomacia multidimensional do governo Lula (2003-2010). Contexto Internacional, Rio de Janeiro, vol. 37, no 1, janeiro/abril 2015, p. 143-184. 
63 | InterAção

SOUTO MAIOR, Luiz Augusto. O Pragmatismo Responsável. In:

ALBUQUERQUE, José Augusto Guilhon (org.). Sessenta Anos de Política Externa Brasileira (1930-1990). 1996.

VIGEVANI, Tullo; CEPALUNI, Gabriel. A política externa de Lula da Silva: a estratégia da autonomia pela diversificação. Contexto internacional, 2007.

VIZENTINI, Paulo Fagundes. A política externa do regime militar brasileiro: multilateralização, desenvolvimento e construção de uma potência média, 19641985. Porto Alegre: UFRGS, 1998.

Relações internacionais do Brasil: de Vargas a Lula. São Paulo:

Editora Perseu Abramo, 2008. 